\title{
Hierarchical Composites Made Entirely from Renewable Resources
}

\author{
Jonny J. Blaker, Koon-Yang Lee, and Alexander Bismarck* \\ Polymer and Composite Engineering (PaCE) Group, Department of Chemical Engineering, Imperial College London, \\ South Kensington Campus, London, SW7 2AZ, UK
}

\begin{abstract}
Recent interest in the utilisation of greener materials has reinitiated the interest in natural fibres and/or fibrils as reinforcement for polymers. However, such bio-based composites often exhibit properties that fall short of expectations due to (i) inadequate processing conditions, resulting in filler agglomeration and poor filler dispersion within the matrix, (ii) variations in natural fibre properties, often due to geographical and seasonal variability, (iii) anisotropy of the natural fibres themselves, (iv) high linear coefficient of thermal expansion for natural fibres and (v) the incompatibility between typically hydrophilic natural fibres and hydrophobic polymer matrices resulting in poor interfacial adhesion between the phases. Chemical modification of natural fibres is often performed to enhance the fibre-matrix interface. A new type of modification, which involves depositing a coating of nanosized cellulose onto natural fibres or dispersing nano-sized cellulose in natural fibre reinforced composites, has been shown to improve the fibre-matrix interface and the overall mechanical performances of such composites, which we term hierarchical (nano)composites. Such composites are also known as multiscale, nanoengineered or nanostructured composites. This paper reviews the current progress of green hierarchical (nano)composites made entirely from renewable materials. As a backdrop, here we look at how nature organises structures across different length scales. We discuss techniques to achieve percolated nanofiller networks within the matrix, at low-medium loading fractions (typically $6-10$ vol.\%) and processing routes to achieve high loading fractions, then focus on those used to produce truly hierarchical structures in terms of their processing and resultant properties. By creating hierarchical structures within bio-based composite materials we expect to match and improve upon non-renewable polymers.
\end{abstract}

Keywords: Hierarchical, Biorenewable, Composites, Cellulose, Mechanical Properties.

\section{CONTENTS}

1. Introduction . . . . . . . . . . . . . . . . . 1

1.1. Some Examples of Hierarchy in Nature . . . . . . . . . . 3

1.2. Challenges in Engineering Hierarchical Structures in Synthetic Materials . . . . . . . . . . . . . .

1.3. Carbon Fibre Based Hierarchical Nanocomposites for High Performance Applications . . . . . . . . . . . . . . . .

2. A Focus on Cellulose as Greener Nano-Reinforcement . . . . . .

2.1. Bacterial Cellulose as the Source of Cellulose Nanofibrils . . . . . . . . . . . . . . . . . .

2.2. Cellulose Nanocrystals . . . . . . . . . . . . . . . . . . . . .

3. Cellulose Nanocomposites . . . . . . . . . . . . . . . . .

3.1. At Low to Medium Cellulose Loadings, Percolated Network Formation . . . . . . . . . . . . . . . . .

3.2. Novel Techniques to Reinforce Matrices with

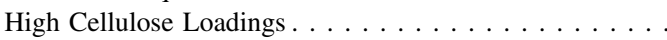

4. Truly Renewable Hierarchical (Nano)composites . . . . . . . .

5. Conclusions and Outlook ................

*Author to whom correspondence should be addressed.

Email: a.bismarck@imperial.ac.uk
Acknowledgments ......................... 15

References......................... 15

\section{INTRODUCTION}

Sustainable development, the need to identify alternatives to fossil resources, green technology and chemistry, reducing the effects of global warming and waste production; these are the hot topics for the plastics industry. The main issue now is: how do we deal with production and end-of-life waste of plastic materials? This problem is strongly connected with the 'Big Four' polymers: polypropylene (PP); polyethylene (PE); polyvinylchloride (PVC) and polystyrene (PS). ${ }^{1}$ So far, plastic waste has generally been regarded as non-recyclable. Landfill and incineration are becoming more expensive due to European Union (EU) waste legislation. ${ }^{2}$ A further EU legislation ${ }^{3}$ allows an incineration quota of just $5 \%$ for all end-of-life 
passenger cars and light commercial motor vehicles by the year 2015. Although much work has been directed towards biodegradable polymers, their application in everyday life remains somewhat limited, due to expensive raw materials and poor mechanical properties. For instance, poly(lactic acid) (PLA), which has already found commercial applications, has limited melt strength and low heat distortion temperature. ${ }^{4}$ It is clear that the mechanical properties of renewable polymers lag behind those of the petroleum derived polymers for commercial use. A composite strategy, combining bio-based/renewable polymers as matrices with renewable reinforcements could be used to bridge the aforementioned property performance gap. While many natural fibres are available, their properties are affected by seasonal and geographical variability ${ }^{5}$ unlike synthetic carbon, glass or polymer fibres with well defined dimensions and properties. Significant research efforts, particularly in the last 15 years have resulted in some promising renewable composite materials. However, these products often fall short of expectation due to problems in achieving suitable dispersion, agglomeration and restrictions to low (nano-filler) loading levels, owing largely to the constraints of traditional polymer processing and incompatibilities between reinforcement and matrix phases. We now look to adapting lessons learned from nature and the development of new manufacturing techniques to produce renewable hierarchical composites, i.e., fibre reinforced nanocomposites with their structures ordered across different length scales. To address some of these challenges we have to use nano-scale reinforcements, which have the inherent advantage of providing large surface areas. One strategy to achieve this is through the creation of percolated networks, where we can use smaller quantities of the reinforcement (typically $>6$ vol.\% relative to the matrix). We are often able to utilise elements of traditional polymer processing in this approach. Another strategy is to use long aspect reinforcements arranged in an aligned and staggered structure at high loading fractions, as are frequently found in nature ( $>50 \mathrm{vol} . \%$ ), for example wood itself. The material's performance is significantly improved as long as we (i) optimally engineer the filler distribution throughout the matrix and (ii) their interfacial adhesion to ensure

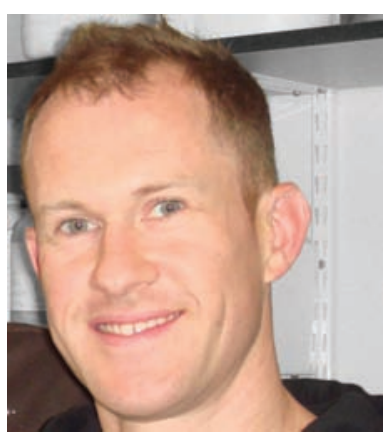

Jonny J. Blaker is a Post-doctoral Research Associate within the Polymer and Composites Engineering (PaCE) Group, Department of Chemical Engineering, Imperial College London, UK. His current research interests are in the fields of bio(medical)materials/device development, and (hierarchical) renewable nanocomposite materials. Prior to this he completed a one-year Medical Research Council (MRC, UK) funded 'discipline-hopping' post-doctoral research position within the Burdette Institute of Gastrointestinal Nursing, Kings College London. He holds a Ph.D. in Biomaterials for Bone Tissue Engineering (2007, Imperial College London, UK), an M.Sc. in Composite Materials (2002, Imperial College London, UK) and has a professional background in design engineering.

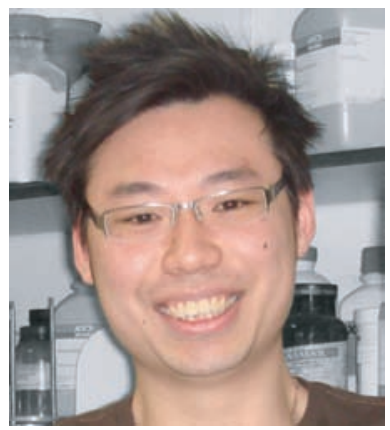

Koon-Yang Lee completed his Masters of Engineering (MEng) degree in the Department of Chemical Engineering, Imperial College London, UK. He is now pursuing his Ph.D. degree within the Polymer and Composite Engineering (PaCE) Group in the same department. His research focuses on the design and fabrication of green hierarchical nanocomposites, in particular surface and interface engineering to enhance composite performance and the application of particle-stabilised (Pickering) emulsions and foams.

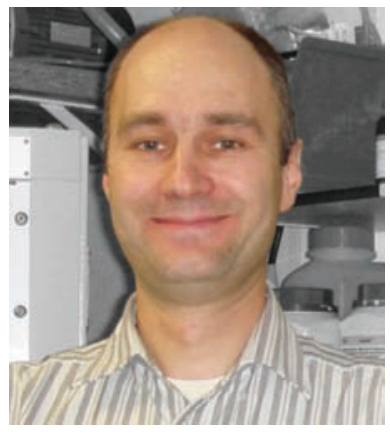

Alexander Bismarck is Professor of Polymer Materials in the Department of Chemical Engineering, Imperial College London, UK. In 2003 he founded the Polymer and Composites Engineering (PaCE) Group. The main focus of his group is on the development, engineering and processing of hierarchical composite materials, truly green materials, the production of microbial cellulose and bio-based composites, as well as on the synthesis, characterisation and application of responsive polymer microgels for fluid loss and viscosity control, and macro porous polymer materials for various applications. 
sufficient stress transfer. The challenges that obstruct such completely renewable hierarchical composites are the:

1. availability of low-cost, abundant and renewable nanoreinforcements.

2. optimisation of the dispersion of nano-reinforcements in the matrix, while maintaining the matrix processability to allow further reinforcement by conventional reinforcing fibres.

3. optimisation of the adhesion between matrix and microas well as nano-scale reinforcements.

4. ability to orient the reinforcements in an aligned, staggered fashion at high loading fractions.

This paper reviews the progress to date towards the realisation of hierarchical composite materials based on renewable resources and assesses the potential of these materials and the strategies to create a new generation of advanced renewable materials. Interest is growing in the development of renewable hierarchical composites, in which (micro- or nano-) fibrillated cellulose, cellulose nano-fibrils or nano-cellulose crystals are utilised in conjunction with conventional natural micrometre-sized fibres. The implications of these strategies on composite processing and performance are discussed. Aspects seen as important towards the development of renewable hierarchical composites are drawn on from examples in nature and synthetic materials found in the literature for hierarchical high performance composites, renewable and partially renewable (nano)composites.

\subsection{Some Examples of Hierarchy in Nature}

Ordered and complex hierarchical structures are observed in biological nanocomposites, such as, wood, bone, teeth and mollusc shells (e.g., nacre), which attain high mechanical performance from relatively weak constituent matter by structuring it across different length scales. ${ }^{6-9}$ Compared with their constituent phases, biological nanocomposites can have strengths and toughnesses orders of magnitude higher. Moreover, this property amplification occurs in a non-additive manner, going beyond the simple rule of mixture. ${ }^{6,7,9}$ It is our challenge to exploit the mechanisms and opportunities of multi-scale assembly to synthetic composite materials. Most of the structural materials used in nature are polymers or ceramic/polymer matrix composites, frequently featuring fibres as design motifs. Biological materials exhibit ordered complex, hierarchical structures that synthetic composites cannot currently achieve. Translating the architectural features that are found in nature at the micro and nano-scales to real synthetic macro-scale structural materials is a huge challenge. Key differences in the way that these hierarchical structures are created are the paradigms of growth in nature and fabrication in synthetic materials. However, unlike their natural counterparts, synthetic materials are not limited by nature's physiological requirements and environmental constraints, e.g., temperature and the prerequisite for voids to permit fluid transfer and nutrient exchange. A recent detailed review of the mechanical properties of biological nanocomposites, their structural hierarchy and the mechanical principles behind the microstructures of these materials has been given by $\mathrm{Ji}$ et al. ${ }^{8}$ Luz and $\mathrm{Mano}^{9}$ have reviewed recent attempts to develop novel synthetic materials and coatings inspired from natural bio-composites. Nature renders nominally brittle mineral crystals insensitive to crack-like flaws by confining them to the nanoscale. This, in combination with soft matrices capable of absorbing energy, results in optimised and resilient biocomposites. This flaw-tolerance property at the nanoscale can propagate to larger length scales via hierarchical design. The principle of the staggered arrangement of hard phases in soft matrices, which, in combination with sufficiently high aspect ratio reinforcement phases and a large modulus ratio between the soft and hard phases, leads to a special load transfer path, the mechanism of large deformation and energy dissipation in the soft phase and the presence of a strong interface between soft and hard materials is necessary.

Graded and anisotropic cellular structures are common in nature, giving good specific properties. In situations where there is a preferred loading direction, like the vertical direction of gravity in the human vertebral bone their structures are such that the material is placed where it is mechanically needed. A synthetic analogy is the truss like structural arrangement that forms the Eiffel tower. ${ }^{10}$

Taking bone as an example, the deformation mechanisms of the protein matrix and mineral reinforcement vastly differ. The deformation of the mineral crystals is predominantly elastic to failure, whereas the proteins undergo very large deformation at their limiting strength via unfolding of their molecular structures. The strength of these proteins is much smaller compared to that of the minerals. ${ }^{11}$ Nature balances the large strength differences between matrix and reinforcement by using the aspect ratios of the mineral phases, such that the softer and weaker protein matrix is subjected to proportionally smaller stress. Their staggered structure serves to balance stiffness and toughness.

The nanostructure of bone consists of high aspect ratio plate-like mineral crystals of carbonated hydroxyapatite (2-4 $\mathrm{nm}$ in thickness and up to $100 \mathrm{~nm}$ in length), embedded and staggered in a parallel arrangement in a collagen-rich protein matrix. ${ }^{11}$ These mineralised collagen fibrils ( $\sim 100 \mathrm{~nm}$ in diameter) constitute the basic building block of bone, ${ }^{7}$ the fibrils themselves are an assembly of triple helical collagen molecules (300 nm long and $1.5 \mathrm{~nm}$ thick), adjacent collagen molecules within the fibrils are staggered along the axial direction, generating a pattern of gap zones $\sim 35 \mathrm{~nm}$ in length and overlap zones $\sim 32 \mathrm{~nm}$ in length within the fibril. The protein matrix, despite its low elastic modulus is sufficient for stabilising individual mineral crystals against localised buckling, 
as its confinement in a hard-soft structure coerces buckling in a higher mode (compared to buckling of slender free-standing plates). ${ }^{11}$ The protein molecules in the soft collagen-rich matrix are able to unfold as well as slip along the protein-mineral interface. It is advantageous to let the interface have the same strength as the matrix phase to maximise the deformation range of the comparatively soft matrix. The soft matrix in bone has a relatively high volume fraction $(\sim 60 \%)$ and can be a few orders of magnitude softer than both the mineral crystals and bone.

Wood is a cellular solid, consisting of hard, crystalline cellulose fibrils, embedded in an amorphous hemicellulose and lignin matrix, arranged into long prismatic cells. ${ }^{7,12,13}$ Cellulose fibrils in each of the adjacent cells run according to a right-handed helix. ${ }^{7}$ At the hundred micrometrescentimetre scale, wood can be regarded as a cellular material; the parameters varied at this hierarchical level include the diameter and shape of the cell cross-section and the thickness of the cell wall. The ratio between cell cross-section and cell wall thickness determine density, these variations can be adapted in response to biological and mechanical needs. Wood deforms by the shearing of soft matrix between stiff cellulose fibres, the stiff fibres are aligned in a soft hemicellulose-lignin matrix. In wood, hemicelluloses are attached with one end to the crystalline parts of cellulose fibrils. The other ends form a hydrogellike matrix, suspected to be via hydrogen bonding. ${ }^{14,15}$ Tensile or compressive deformation of the cell wall along its axis is transformed into a shearing of the hemicellulose matrix, beyond a critical shear stress, the matrix starts to flow, probably by opening and reforming hydrogen bonds. ${ }^{7}$ Via this mechanism, the stiff fibrils carry most of the load, practically without deformation, with most of the deformation taking place via shearing of the deformable hemicellulose/lignin matrix ${ }^{13}$ (see Fig. 1). Strong binding between the matrix and the fibrils is an important condition for this type of deformation mechanism, the strong binding is enabled by the chemical similarity of cellulose fibrils and hemicelluloses. ${ }^{7}$ The matrix must adhere very strongly to the fibres to avoid failure of the interface. Nature has evolved amphiphilic molecules for this type of function.

\subsection{Challenges in Engineering Hierarchical Structures in Synthetic Materials}

Deficiencies of synthetic nanocomposites are related largely to the difficulty in attaining large volume fractions of nano-reinforcement phases in combination with a lack of control over their arrangement. Key challenges in biomimetic synthesis include the control of size, geometry and alignment of nanostructures and the development of higher levels of hierarchy. We are attempting to replicate and improve upon in the lab what nature has accomplished through evolution in designing hierarchical nanocomposites as material systems. Moreover, it is difficult to achieve

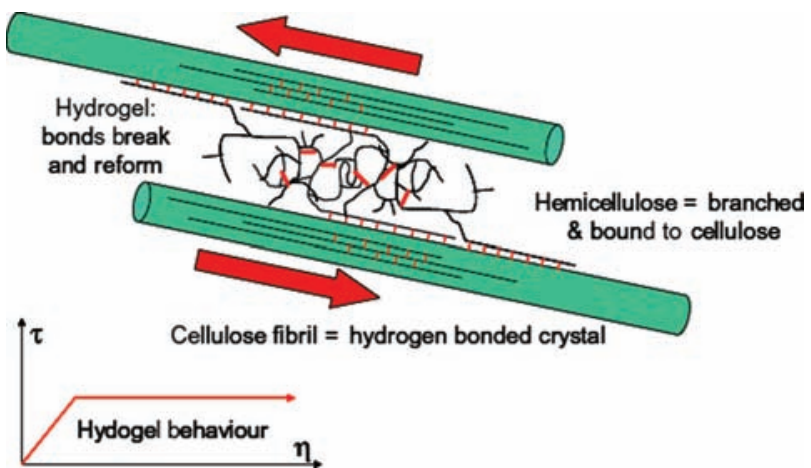

Fig. 1. Deformation model of hemicelluloses in the plant cell wall. Tensile or compressive deformation of the cell wall along its axis is transformed into a shearing of the hemicellulose matrix (arrows). The matrix is assumed to exhibit a mechanical response as inset, shear stress $\tau$, versus shear strain $\eta$. Beyond a crtical shear stress, the matrix starts to flow, suspected to be due to the opening and reforming of hydrogen bonds. Reprinted with permission from [7], P. Fratzl and R. Weinkamer, Prog. Mater Sci. 52, 1263 (2007). (C) 2007, Elsevier.

an effective load transfer between the polymeric matrix phase and the nano-scale reinforcements, coupled with our lack of understanding of the interactions of the constituent phases over different length scales. Many experiments are being conducted to synthesise novel biomimetic nanocomposites in the lab. ${ }^{9}$ There are some successful synthetic nanocomposites, including, the replication of nacre, with an ordered brick-and-mortar arrangement of organic and inorganic layers and ionic cross-linking of macromolecules in organic layers. This has been achieved using a layer-bylayer assembly method, with the sequential deposition of polyelectrolytes and clays. ${ }^{16,17}$

\subsection{Carbon Fibre Based Hierarchical Nanocomposites for High Performance Applications}

Conventional continuous fibre reinforced composites have made a huge impact in recent decades in the aerospace, transport and oil and gas industries. Their superior specific properties, chemical resistance and excellent inplane tensile properties make them suitable for many structural applications. These high performance materials are generally produced from unidirectional tapes or two-dimensional woven fabrics and consequently have impaired compression and interlaminar properties. Momentum is building therefore to alleviate largely matrix dominated properties through the development of hierarchical high performance composites, in which a nanoscale carbon nanotube (CNT) reinforcement is utilised in conjunction with a traditional microscale fibre reinforcement, as reviewed recently. ${ }^{18}$ There are broadly two strategies to produce CNT-based hierarchical composites: (i) a dispersion of CNTs in the matrix and (ii) their direct attachment onto the primary carbon fibre surface (see Fig. 2). 'Hairy' CNT coated carbon fibres have been created, in an effort to improve fibre/matrix stress-transfer (see Fig. 2). 


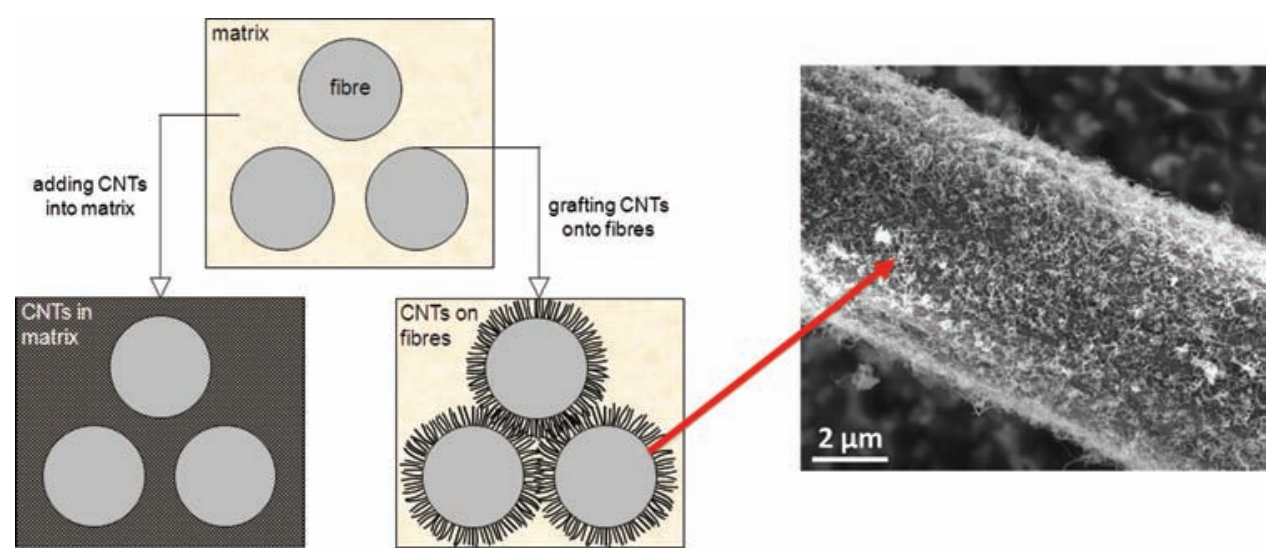

Fig. 2. Schematic diagram of conventional fibre-reinforced polymer composites and CNT-based hierarchical polymer composites. The far right image is a scanning electron micrograph depicting CNTs grown on a carbon fibre (arrowed). Reprinted with permission from [18], H. Qian et al., J. Mater. Chem. 20, 4751 (2010). () 2010, RSC Publishing.

CNT attachment onto carbon fibre surfaces is an effective method to improve fibre surface area, creating mechanical interlocking and local stiffening at the fibre/matrix interface. ${ }^{18}$ In this way, the nanoscale reinforcement, radial to the fibres, extends into the surrounding matrix in an effort to stiffen the matrix and provide increased lateral support for the load-bearing microscale fibres. ${ }^{18}$ Through this method, microbuckling may be prevented, which is the critical composite failure mode associated with fibres in longitudinal compression.

Through these hierarchical approaches, matrixdominated properties, such as interlaminar shear strength (ILSS) have been improved by between $8-30 \% .^{19-22}$ Failure often involves pull-out or rupture of the nanoreinforcements, it can be inferred that the matrix toughness is improved with additional energy consumption and ILSS. The addition of CNTs into conventional glass fibre/epoxy systems has been reported to increase fatigue life due to increased energy absorption and inhibition of damage propagation. ${ }^{23}$ As an alternative to reinforcing the entire matrix, researchers have demonstrated toughening of the interlaminar regions by introducing CNT-rich layers in between the composite plies, ${ }^{24-27}$ incorporating aligned CNT mats, resulted in ILSS improvements of up to $45 \%$. In this case the CNTs in the interlaminar region seem to arrest delamination due to pull-out, interleaving and bridging toughening mechanisms. ${ }^{26-28}$ The flexural properties of composites containing CNT-grafted carbon performs have improved by 5-75\%..$^{29-32}$ These results point towards the potential of creating hierarchical structure within composite materials to improve the mechanical performances of traditional composites.

\section{A FOCUS ON CELLULOSE AS GREENER NANO-REINFORCEMENT}

Cellulose is a natural occurring hydrophilic homopolymer that can be obtained mainly from parenchymal plant walls (e.g., cotton) but also certain bacteria (e.g., Acetobacter xylinum) and tunicates (sea squirts) produce cellulose. Cellulose is composed of $\beta$-D-glucopyranose units, which are connected together by $(1 \rightarrow 4)$ glycosidic bonds. ${ }^{5}$ A native cellulose molecule is at least $5000 \mathrm{~nm}$ long, with a degree of polymerisation of about $10,000^{33}$ (see Fig. 3). These cellulose molecules are linear and the forces responsible for the aggregation of linear cellulose molecules into microfibrils are hydrogen bonds and van der Waals forces. This molecular aggregation is responsible for the unique properties of plant cell walls. Hydrogen bonding requires close proximity between adjacent hydroxyl groups around $0.25-$ $0.35 \mathrm{~nm} .{ }^{33}$ Cellulose has a strong affinity to itself and other materials that contain hydroxyl groups. ${ }^{33}$ Due to this, cellulose can be well dispersed in water and a variety of polar solvents. Cellulose associates with water molecules by forming up to several layers of water molecules on its surface. ${ }^{34}$ However, it can only be dissolved in strong acids and ionic liquids. ${ }^{35}$ Cellulose is thermally stable, in terms of its chemical composition up to $180{ }^{\circ} \mathrm{C}$, then starts to discolour from white to yellow-brown, even before abrupt

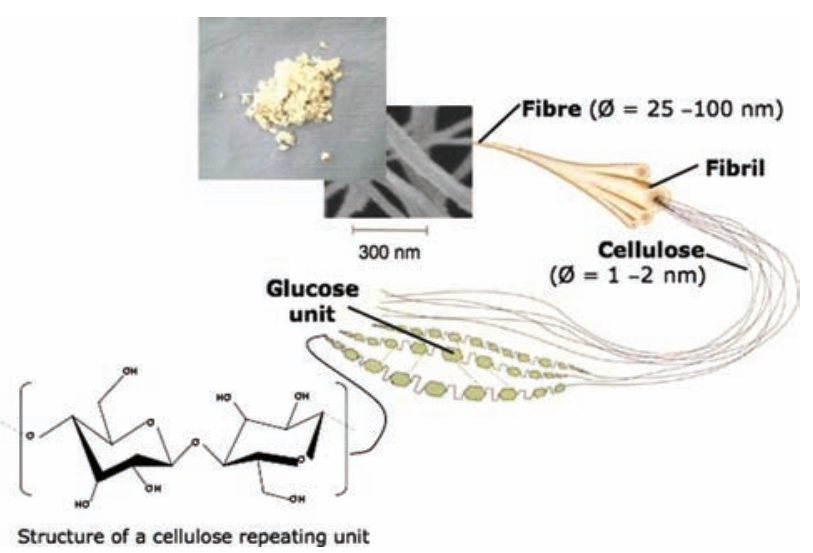

Fig. 3. Schematic diagram showing the hierarchical structure of bacterial cellulose. 
structural changes occur (the hydrogen bonded $\mathrm{OH}$ groups become unstable) at $220{ }^{\circ} \mathrm{C}$ and a further decomposition step is reported to occur at around $300{ }^{\circ} \mathrm{C} .{ }^{36}$

\subsection{Bacterial Cellulose as the Source of Cellulose Nanofibrils}

The main difference between cellulose synthesised by plants and bacteria is that plant-synthesised cellulose usually also contains hemicellulose, lignin and pectin while cellulose produced by bacteria on the other hand, is pure cellulose without foreign substances. ${ }^{37}$ Bacterial cellulose can be produced by many different strains of bacteria from the Acetobacter species $^{38,39}$ and has dimensions already in the nanometre size range, as shown in Figure 4. The bacteria produce highly ordered cellulose fibrils typically 20 to $50 \mathrm{~nm}$ wide, which themselves are constituted of fibrils $2 \mathrm{~nm}$ to $4 \mathrm{~nm}$ in diameter (Fig. 3). ${ }^{40}$ Bacterial cellulose is commonly produced in agitated or static culture conditions, a detailed study of the synthesis by and the function of cellulose for bacteria can be found in literature. ${ }^{41}$ A source of bacterial cellulose commercially available to researchers is nata de coco (floating gel), a sweet dessert (coconut gel in syrup) originating from the Philippines and produced in large volumes. Nata de coco is in fact the pellicle within which the bacteria produce cellulose at the medium-air interface. The bacterial cellulose purification for research purposes can be done by immersing the gel-like substance in a dilute solution of $\mathrm{NaOH}$ at $80{ }^{\circ} \mathrm{C}$ to remove bacterial cell debris and sugars, ${ }^{42}$ followed by washing and centrifugation until the $\mathrm{pH}$ returns to neutral. $\mathrm{X}$-ray diffraction (XRD) of bacterial cellulose has shown that it is cellulose I, in which two cellulobiose units are arranged parallel in a unit cell. These cellulose molecules tend to have a specific planar orientation in dried films. ${ }^{43}$ Bacterial cellulose has also been applied to produce hierarchical composite fillers in situ ${ }^{44-46}$ whereby the bacterium

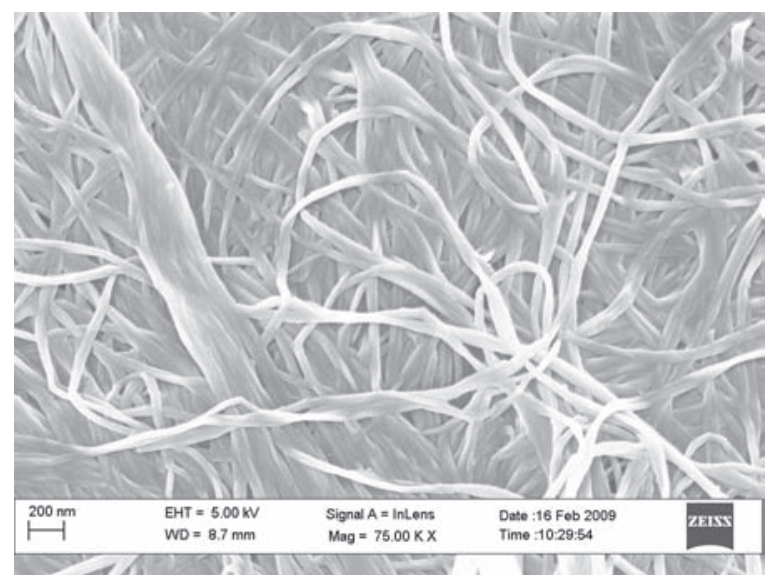

Fig. 4. Scanning electron micrograph of bacterial cellulose, depicting the ribbon-like nano-fibres with diameters between 20 and $50 \mathrm{~nm}$. Reprinted with permission from [72], K. Y. Lee et al., Compos. Sci. Technol. 69, 2724 (2009). (C) 2009, Elsevier.
Acetobacter xylinium was cultured in the presence of natural fibres and found to deposit bacterial cellulose onto natural fibres. This makes bacterial cellulose much more appealing than other types of cellulose as the interfacial adhesion between cellulose and polymers can be enhanced in situ, using bacteria as a tool to construct a nano-scale to micro-scale hierarchical structure, not requiring any post modification of the cellulose.

Bacterial cellulose has high specific properties and has been reported to have a Young's modulus of $138 \mathrm{GPa}$, tensile strength of 2 to $3 \mathrm{GPa}^{47}$ and a very low coefficient of thermal expansion $10^{-7} \mathrm{~K}^{-1} \cdot{ }^{37}$ Bacterial cellulose has already been successfully used to produce absorbent materials for burns and skin graft applications, the product Biofill, ${ }^{39}$ reinforcement in paper products by Mitsubishi Paper Mills Company, ${ }^{37}$ an electro-acoustic transducer by Sony Corporation ${ }^{48}$ and also as reinforcement in optically transparent films by impregnating resins into bacterial cellulose sheets to be used as substrates for displays. ${ }^{49}$

\subsection{Cellulose Nanocrystals}

Cellulose nanocrystals (CNCs), also termed cellulose nanowhiskers (CNWs) are some of the most studied cellulosic materials for reinforcing polymer matrices. They often give rise to strong and tough hydrogen-bonded networks, markedly improving the properties of composite materials. ${ }^{16,50-53} \mathrm{CNCs}$ have been subject to a wide range of research in nanocomposites including those with natural and synthetic matrices and as substrates in roll-to-roll printing applications, in particular for use in organic light emitting diode (OLED) displays. ${ }^{54}$ To name a few: starch, ${ }^{55}$ cellulose acetate butyrate (CAB) ${ }^{56}$ $\mathrm{PLA}^{57}$ from renewable resources and $\mathrm{PP}^{58} \mathrm{PVC}^{59}$ and poly(oxyethylene) (POE) from petrochemical resources. ${ }^{60}$ $\mathrm{CNCs}$ can be derived from many different cellulosic sources such as cotton, wood pulp, sugar-beet pulp, tunicates and bacterial cellulose. ${ }^{61-63}$ Rod-like CNCs can be obtained via acid hydrolysis, which serves to remove the amorphous region of the cellulose and hence structural defects, leaving behind the crystalline structure only. Whilst hydrochloric acid has been utilised, sulphuric acid hydrolysis is often preferred as it results in sulphonation of the cellulose surface ${ }^{64}$ and the negatively charged groups act to improve the stability of CNCs in aqueous suspensions. ${ }^{16,65-67}$ Yields of CNCs obtained from cellulose derived from Norway spruce trees have been reported to reach up to $30 \%$ with a length of between $200 \mathrm{~nm}$ and $400 \mathrm{~nm}$ and width of $10 \mathrm{~nm} .{ }^{68}$ The stiffnesses of CNCs from various sources are summarised in Table I. CNCs obtained from tunicates have a high tensile modulus reported to be $\sim 140 \mathrm{GPa}$, with dimensions typically $26 \mathrm{~nm}$ in thickness and aspect ratios of 70-85. ${ }^{67,69}$ Such CNCs are known to form nematic liquid crystals in suspension. These chiral-nematic orderings can be preserved 
Table I. A comparison of physical properties of cellulose fibril processed and derived from different methods and sources.

\begin{tabular}{lcc}
\hline Type and origin of cellulose & $\begin{array}{c}\text { Young's } \\
\text { modulus [GPa] }\end{array}$ & Crystallinity [\%] \\
\hline $\begin{array}{c}\text { Tunicate } \\
\text { (cellulose nano-whiskers) }\end{array}$ & 143 & $83-88$ \\
$\begin{array}{c}\text { Bacterial cellulose } \\
\quad \text { (Glconacetobacter Xylinum) }\end{array}$ & $114-138$ & 89 \\
$\begin{array}{c}\text { Cotton } \\
\text { (cellulose nano-whiskers) }\end{array}$ & $57-105$ & 99 \\
$\begin{array}{c}\text { Flax Fibre } \\
\text { (Micro crystalline cellulose) }\end{array}$ & 25 & 96 \\
\hline
\end{tabular}

Source: Reprinted with permission from [103], R. Rusli and S. J. Eichhorn, Appl. Phys. Lett. 93 (2008). (C) 2008, American Institute of Physics; from [106], S. J. Eichhorn and R. J. Young, Cellulose 8, 197 (2001). (C) 2001, Springer.

after liquid evaporation. ${ }^{70}$ At dilute concentrations in aqueous solutions, ordered domains form. As the concentration increases the coalescence of these ordered domains results in an anisotropic phase, characterised by the unidirectional self-orientation of CNCs.

Cellulose nanofibres (CNF) and CNCs have good potential as reinforcements, if randomly orientated and well dispersed in polymer matrices and especially if they can be aligned. The incorporation of optionally chemically-modified CNFs or CNCs can provide functional advantages relating to electrical conductivity ${ }^{71}$ magnetic properties, optical properties such as transparency, and biological interactions. ${ }^{49,54,71}$ Chemical modifications include organic acid esterification, ${ }^{72,73}$ silylation, ${ }^{74}$ TEMPO-oxidation, ${ }^{75-77}$ surfactant adsorption ${ }^{70}$ and polymer grafting. ${ }^{78}$ For a more detailed review of the chemical and physical traits of $\mathrm{CNCs}$, their modification and self-assembly in different media and application in nanocomposites the reader is referred to Habibi et al. ${ }^{70}$ Such chemical modifications are often conducted to enhance dispersion and tune the adhesion of the cellulose with hydrophobic polymer matrices in nanocomposites. Unmodified cellulose is extremely hydrophilic; CNCs disperse well in aqueous solution. However, using water as the medium for CNCs limits the choice of matrices to water-soluble polymers. An alternative to improve the dispersion of CNCs in hydrophobic polymer matrices is through the use of surfactants. ${ }^{79}$ However, this approach has the limitation that a large amount of surfactant, usually four times larger than the amount of cellulose, is required due to the high surface area of the CNCs. ${ }^{53}$ Chemical surface modification $\mathrm{CNC} / \mathrm{CNF}$ s can be performed to introduce hydrophobic groups onto the cellulose and represents a more viable alternative; indeed there are a large number of hydroxyl groups present on the cellulose surface available for functionalisation. CNF and $\mathrm{CNC}$ modification should be restricted to the surface such that their crystalline structures and, therefore, mechanical properties are preserved, although in the production of all-cellulose nanocomposites the concomitant modification of the bulk is sometimes desirable ${ }^{80}$ Fischer esterification simultaneously occurring during the hydrolysis of amorphous cellulose chains and acetylation has been used to obtain CNCs with tuned surface energy. ${ }^{73}$ It is also possible to conduct esterification in the gasphase, although the CNCs must be dried first. ${ }^{81}$ Indeed, $\mathrm{CNCs}$ form rigid three-dimensional networks above a certain whisker percolation concentration because of hydrogen bond formation between the individual whiskers. ${ }^{64}$ Frequently, in order to achieve a dispersion of CNCs in a solvent, the CNCs must either undergo freeze-drying procedures in order to avoid hornification of the dry cellulose or solvent exchange steps. The modification of CNCs aforementioned can break the percolating hydrogenbonded networks that affect the macroscopic properties of the resulting nanocomposite.

\section{CELLULOSE NANOCOMPOSITES}

Although renewable polymer matrix nanocomposites have demonstrated improvements of a wide range of composite properties, in comparison to neat polymer matrix materials, absolute increases, especially those of mechanical properties have been disappointing in many cases. Renewable nanocomposites have been hampered by difficulties in achieving a strong interface between the nanofiller and the matrix and in achieving good dispersion, the formation of a percolated network, alignment and difficulties with processing techniques to achieve high loading fractions. In the following sub-sections we review the progress in the development of techniques to leverage the properties of $\mathrm{CNFs} / \mathrm{CNCs}$ and in some cases microfilbrillated cellulose (MFCs) in the production of composites with low and high loadings fractions, respectively. Lessons from these are applicable in the design of new hierarchical renewable composites, which are covered in more detail in Section 4.

\subsection{At Low to Medium Cellulose Loadings, Percolated Network Formation}

In this section, techniques to prepare organised structures and induce the nucleation of crystal growth within the polymer matrix using traditional polymer processing methods are covered. For further reviews on processing techniques applied for polysaccharide reinforced nanocomposites the reader is referred to recent reviews by Dufresne $^{82}$ and Siro and Plackett. ${ }^{2}$

The formation of a rigid percolating $\mathrm{CNC}$ network cemented together by hydrogen bonds is key to the realisation of nanocomposites. Processing and the viscosity of the system will affect the ability of a percolated network to form. Solvent cast and sol-gel methods give high mechanical performance as the network is formed prior to polymer addition. Solvent casting allows percolated network formation due to the slow drying of the solvent. Whereas thermal processing and the high viscosities typical for polymer 
melts hinder interaction between CNCs, the shear exerted during processing will also induce alignment. The nature of the polymer matrix and the surface energy of the CNCs will affect the ability of the CNCs to form a percolated network whereby the CNCs are joined by hydrogen bonds.

Liu et al. ${ }^{83}$ prepared CNC reinforced glycerol plasticised starch composite films. They extracted the CNCs from bamboo using a method of combined $\mathrm{HNO}_{3}-\mathrm{KClO}_{3}$ treatment and sulphuric acid hydrolysis. CNCs were dispersed into a partially gelated mixture of starch and glycerol (initially consisting of $6 \mathrm{wt} \%$ pea starch and $2.4 \mathrm{wt} \%$ glycerol in water), which was stirred and heated at $80{ }^{\circ} \mathrm{C}$ for $30 \mathrm{~min}$, the CNCs themselves dispersed in water at a concentration of $10 \mathrm{wt} \%$ were added to the mixture and stirred for a further $20 \mathrm{~min}$ at $80^{\circ} \mathrm{C}$. The mixture was degassed under vacuum and cast into polystyrene moulds. The loading of CNCs was varied from 1 to $20 \mathrm{wt} \%$. The arrangement of the CNCs was dependent on their concentration in suspension. At low concentrations (i.e., $0.1 \mathrm{wt} \%$ ) the CNCs assembled into organised leaf-like structures, which were described as leaf nervations but tended to agglomerate at high concentration (i.e., $10 \mathrm{wt} \%$ ). The incorporation of CNCs resulted in improved mechanical properties of the nanocomposites and served to reduce water uptake, the optimal loading level was $8 \mathrm{wt} \%$. Tensile strength and Young's modulus both increased sharply from $2.5 \mathrm{MPa}$ (0\% CNC loading) to $12.8 \mathrm{MPa}$ (8 $\mathrm{wt} \%$ loading) and from $20.4 \mathrm{MPa}(0 \% \mathrm{CNC}$ loading) to $210.3 \mathrm{MPa}$ (8 wt\% loading), respectively.

CNCs are known to act as nucleation agents in semicrystalline polymers, significantly increasing crystallinity in the resultant nanocomposites. ${ }^{58,78,84}$ More polymer crystals are able to nucleate and grow on the large interfacial area of $\mathrm{CNCs}$ and polymer with increasing numbers of nucleating particles. Transcrystalline regions have been reported in $\mathrm{CNC}$ reinforced polypropylene (PP) matrix composites, the CNCs act to nucleate PP crystal growth and extend into the semi-crystalline PP matrix. ${ }^{85}$ Many research groups have been filling PLA with $\mathrm{CNFs} / \mathrm{CNCs}$ and MFCs in a combined effort to nucleate PLA crystal growth and reinforce the composite. Ten et al. ${ }^{86}$ prepared bacterial polyester poly(3hydroxybutyrate-co-3-hydroxyvalerate) (PHBV) matrix composites, reinforced with CNCs with loading fractions ranging from 1 to $5 \mathrm{wt} \%$ using a solvent casting method (using dimethylformamide (DMF) as solvent) and polyethyleneglycol (PEG) as a compatibilising agent. Polarised light microscopy demonstrated that the CNCs were an effective nucleation agent for PHBV. Tensile strength, Young's modulus and toughness of PHBV nanocomposites increased concomitantly with increasing CNC concentration. Dynamic mechanical analysis (DMA) revealed that PHBV chain mobility was restrained in the vicinity of the CNCs.
Suryanegara et al. ${ }^{87}$ developed a kneading technique to disperse MFCs to $10 \mathrm{wt} \%$ loadings in PLA. They investigated the deformation behaviour of the composites as a function of PLA crystallinity. Their composites were processed by solvent exchanging MFCs into chloroform from water through acetone via successive re-dispersion and centrifugation cycles, PLA was then added to the mixture following homogenisation to better disperse the MFCs, followed by solvent evaporation and vacuum drying. The composite was then kneaded using a twin rotary roller mixer at $160{ }^{\circ} \mathrm{C}$ at $40 \mathrm{rpm}$ for $15 \mathrm{~min}$, prior to crushing the material into small pieces and subsequent compression moulding at $180^{\circ} \mathrm{C}$. The hot pressed sheets were quenched in liquid $\mathrm{N}_{2}$ to ensure they were in an amorphous state, followed by annealing at times ranging from 0 to $60 \mathrm{~min}$ in between steel sheets maintained at $80{ }^{\circ} \mathrm{C}$. The maximum tensile strength of MFC/PLA was $60.8 \mathrm{MPa}$, comparable to fully crystallised PLA, the Young's modulus of the composite was $4.22 \mathrm{GPa}, 20 \%$ higher than that of fully crystallised PLA. At a crystallinity of $43 \%$ the composite had tensile strength of $66.3 \mathrm{MPa}$ and Young's modulus of 4.45 GPa. However, the strain at break of the MFC/PLA composites decreased from $2.59 \%$ to $2.29 \%$ due to an increased degree of crystallisation. The nanosized cellulose fillers had a huge interfacial area with PLA, which may reduce fracture development in the PLA matrix during non-linear deformation, compensating for the embrittlement of PLA due to its crystallisation. ${ }^{88}$ At crystallinity levels $>17 \%$, the PLA composite containing $10 \%$ MFCs was able to maintain its shape under heating at $110{ }^{\circ} \mathrm{C}$ for $3 \mathrm{~h}$ similarly to the fully crystallised neat PLA sample. In this case the filler restricted the mobility of the polymer chains.

Jonoobi et al. ${ }^{89}$ produced CNF reinforced PLA via twin screw extrusion with loadings up to $5 \mathrm{wt} \% \mathrm{CNF}$. The tensile modulus and strength increased from $2.9 \mathrm{GPa}$ to $3.6 \mathrm{GPa}$ and from $58 \mathrm{MPa}$ to $71 \mathrm{MPa}$, respectively, for nanocomposites with $5 \mathrm{wt} \% \mathrm{CNF}$. The presence of aggregates was marked at higher loadings, with white agglomerates visible to the naked eye. DMA has shown that the CNFs act to restrict the segmental mobility of the polymer chains in their vicinity. ${ }^{89}$ Jonoobi et al. processed their composites by preparing a master batch of CNF dispersed in acetone, which was added into PLA dissolved in an acetone/chloroform mixture, which was left to evaporate, prior to crushing it into a particulate material suitable for extrusion, pelletising and subsequent injection moulding.

Whilst the above ${ }^{87,89}$ shows positive trends to increasing tensile strength and modulus there is conflicting information for such systems in the literature. The general trend for PLA matrix/nanocellulose composites is that the addition of nanocellulose results in an increased elastic modulus but a reduction in tensile strength with increasing volume fraction of nano cellulose loading when processing is performed at an elevated temperature. As an example, 
increases in moduli have been reported from $3.6 \mathrm{GPa}$ to $4.1 \mathrm{GPa}$ and $5 \mathrm{GPa}$ with 0,10 and $25 \mathrm{wt} \%$ microcrystalline cellulose loading fractions, respectively; ${ }^{90}$ whereas tensile the strength of the composites reduced by $\sim 25 \%$ from $50 \mathrm{MPa}$ of neat PLA with loadings of microcrystalline cellulose greater than $10 \mathrm{wt} \%$. Other researchers have found when using recycled cellulose fibres (CreaMix TC 1004) that tensile strength of neat PLA is significantly reduced from $63 \mathrm{MPa}$ with cellulose additions of $>10 \mathrm{wt} \%$ and further reduced to $39 \mathrm{MPa}$ in the presence of $40 \mathrm{wt} \%$ cellulose. ${ }^{91}$ Whereas, elastic moduli increased from $2.7 \mathrm{GPa}$ through $3.2 \mathrm{GPa}$ to $6.8 \mathrm{GPa}$ with cellulose loadings of 0,10 and $40 \mathrm{wt} \%$. Many of these effects are due to problems with poor dispersion and nanocellulose agglomeration, typically above $10 \mathrm{wt} \%$ loadings. Whilst there have been some successful thermally processed CNF/CNC-filled hydrophobic polymer matrix composites reported, those with marked improvements contain functionalised CNCs/CNFs. One such example is the extrusion of low-density polyethylene (LDPE) in combination with fatty-acid grafted CNCs. ${ }^{92}$ To counter this juxtaposed effect of cellulose on mechanical properties, efforts have been made to reactively couple microfibrillated cellulose (MFC) with the matrix by adding maleic anhydride (MAH) grafted PLA into the mixture followed by compression moulding. ${ }^{93}$ Tensile strengths were found to increase from $40 \mathrm{MPa}$ for neat PLA to $80 \mathrm{MPa}$ for a mixture of MAH grafted PLA (85 wt $\%$ ) with PLA (10 wt $\%$ ) reinforced by cellulose nanowhiskers ( $5 \mathrm{wt} \%)$, an increase in modulus was also found from 2.9 GPa to $3.9 \mathrm{GPa}$ for the same composite materials, respectively. In addition to using PEG as a processing aid, poly(vinyl alcohol) $(\mathrm{PVOH})$ was also used to improve the dispersion of cellulose nanowhiskers in PLA. ${ }^{57}$ The elastic modulus of the nanocomposites increased from $3.31 \mathrm{GPa}$ (neat PLA) to $3.71 \mathrm{GPa}$ (PLA-PVOH-CNCs), attributed to a higher level of dispersion of the nanowhiskers due to the addition of PVOH, while the tensile strength of the nanocomposites dropped from 71.9 $\mathrm{MPa}$ to $66.5 \mathrm{MPa}$, which was accounted for by the CNC hydrophilicity keeping them in the PVOH phase rather than PLA.

Pei et al. ${ }^{84}$ prepared CNC and silylated CNC filled PLA composites via solution casting, they found that unmodified CNCs formed aggregates in the composites, whereas the silylated CNCs (200 to $300 \mathrm{~nm}$ in length, $15 \mathrm{~nm}$ in width) were dispersed and individualised in PLA, with tensile strength and Young's modulus $>20 \%$ higher than neat PLA, at loadings of just $1 \mathrm{wt} \%$ silylated $\mathrm{CNCs}$, due in part to crystal nucleation from the CNCs. It was demonstrated that both unmodified and silylated CNCs acted as nucleation sites, silylated CNCs were shown to be better dispersed in the matrix, whereas white agglomerates were evident for unmodified CNCs. Pei et al. ${ }^{84}$ reported that strain to failure decreased for both the addition of unmodified and silylated CNC compared to neat PLA.
Whilst hydrophobisation of the cellulose surface hydroxyl groups may serve to reduce hydrogen bonding, it does also reduce agglomeration, improves dispersion and so provides a large surface area for the heterogeneous nucleation and growth of crystals as evident from the polarised optical light microscopy images of the composites shown in Figure $5 .{ }^{84}$ The authors have addressed the industrial problem of slow crystallisation of poly(L-lactide) (PLLA) using these partially silylated CNCs. ${ }^{84}$

PLA matrix/acetylated MFC composite films containing up to $17 \mathrm{wt} \%$ functionalised MFCs have been produced via solvent casting. ${ }^{94}$ The authors dispersed the acetylated MFCs, derived from mechanically fibrillating pulp into nano- to submicrometre wide fibres to form a web-like network in PLA matrices. Acetylation served to reduce hydrogen bonding between MFCs in the composite, however, the inhibition of hydrogen bonding between adjacent nanofibres served to reduce the rigidity of the composite in comparison to the unmodified fibres. The properties of the resulting PLA nanocomposites could be tailored by adjusting both the acetyl content and the amount of MFC. These nanomaterials showed improved filler dispersion, higher thermal stability and reduced hygroscopicity with respect to those prepared with unmodified MFC. The solution-casting method presents disadvantages, especially because large volumes of solvents are required to dissolve the polymer and to disperse the cellulose before processing, which is time consuming and is not so scalable or environmentally sound. In fact, almost any chemical modification of cellulose to improve the interfacial adhesion between hydrophobic polymers will involve the use of solvents.

\subsection{Novel Techniques to Reinforce Matrices with High Cellulose Loadings}

In an attempt to mimic hierarchical structures found in nature (aforementioned), Zhou et al. ${ }^{95}$ developed a lowenergy biomimetic system for the production of a highstrength composite material consisting of self-assembled and nano-structured CNFs, by growing the cellulose producing bacterium Acetobacter, in the presence of the water soluble polymer hydroxyethylcellulose (HEC), which was added to the culture medium. The authors prepared 40-70 $\mu \mathrm{m}$ thick films from both bacteria cultured in unmodified medium (control) and HEC modified medium. Pellicles were first purified and homogenised into aqueous suspensions that were subsequently vacuum filtered to form films, which were then stacked and pressed into thicker films. Individual cellulose fibrils were coated by HEC and self-assembled to form compartmentalised nanofibres, coated by a thin layer $(\sim 0.3 \mathrm{~nm})$ of HEC, a soft, hydrated amorphous polysaccharide. The authors report that the additive seemed to compete with bacterial 


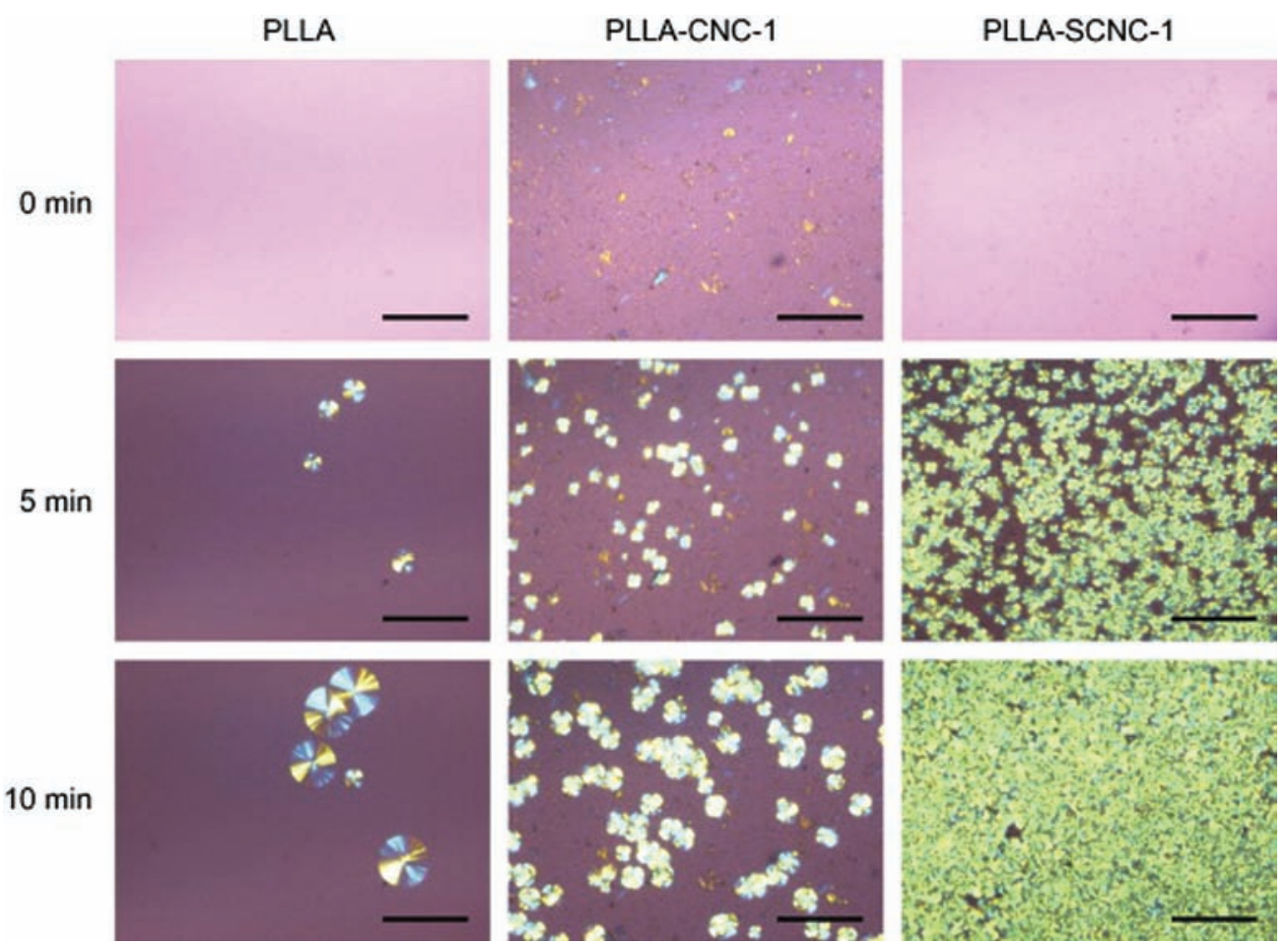

Fig. 5. Polarized optical microscope images of PLLA, PLLA-CNC-1 (unmodified CNCs at $1 \mathrm{wt} \%$ loading), and PLLA-SCNC-1 (silylated CNCs at $1 \mathrm{wt} \%$ loading) acquired on the 0,5 th and 10 th min at $125{ }^{\circ} \mathrm{C}$ after quenching from melts at $210{ }^{\circ} \mathrm{C}$. Scale bar, $200 \mu \mathrm{m}$. Reprinted with permission from [84], A. H. Pei et al., Compos. Sci. Technol. 70, 815 (2010). (C) 2010, Elsevier.

cellulose for hydrogen-binding sites during ribbon formation, leading to the production of thicker fibrils. The tensile strength of nanocomposite films prepared from the compartmentalised cellulose nanofibres was $20 \%$ higher than that of pure bacterial cellulose sheets and wood cellulose nanopapers and $60 \%$ higher than that of conventional bacterial cellulose/HEC blends. The thin nanoscale coating consisting of hydrated HEC significantly increased the mechanical performance of the nanocomposite films by provoking compartmentalisation of individual fibrils. Catastrophic fracture was delayed by the crack-deflecting function of the thin nanofibril coating. In the post-yield region, strain-hardening was observed. The slope of the strain-hardening region was higher for HEC modified bacterial cellulose films, which the authors attribute to the soft, hydrated HEC coating and the resulting increased friction during slippage of nanofibres with respect to each other. They attribute the large post-yield strain region found is likely to involve slippage and reformation of interfibril bonds. ${ }^{95}$ The tensile strength and work to fracture of the bacterial cellulose/HEC films was $289.4 \pm 13.8 \mathrm{MPa}$ and $11.0 \pm 1.0 \mathrm{MJ} \mathrm{m}^{-3}$, as opposed to $225.6 \pm 3.7 \mathrm{MPa}$ and $10.7 \pm 0.5 \mathrm{MJ} \mathrm{m}^{-3}$ for the control bacterial cellulose films, respectively.

Abe et al. ${ }^{96}$ developed a technique to process fibrillated soft wood derived cellulose inherently containing $\sim 28 \%$ lignin and produced compression moulded samples by simply thermally plasticising the lignin itself, obviating the need to forcibly mix cellulose nanofibrils with the matrix during processing. They used a simple one-time grinder treatment to disintegrate pulp to obtain micro- to nanometre-sized lamellar or fibrous fragments composed of high aspect ratio cellulose microfibrils encased in matrix substances including hydrophobic lignin. The fragments were dehydrated via filtration and dried in an oven prior to compression moulding by thermally plasticising lignin without any adhesives or resins. The moisture content was $10 \%$ prior to moulding. Samples were reported to exhibit a plastic-like gloss finish on their surfaces and a high bending strength, $221 \mathrm{MPa}$, greatly exceeding those of conventional plant-based binder-less boards. The moulded products produced constitute a novel form of cellulose nanocomposite, which exploits the inherent compatibility between cellulose microfibrils and matrix substances present in these fragments. Through this method they were able to incorporate stiff nanofillers with high aspect ratios with uniform dispersion at loading of $\sim 50 \mathrm{wt} \%$ cellulose in a composite and obtain a high affinity between the filler and matrix.

Yano et al. ${ }^{97}$ reported the fabrication of optically transparent (nano)composites, reinforced with up to $70 \mathrm{wt} \%$ of bacterial cellulose nanofibrils. The (nano)composite exhibited a low thermal-expansion coefficient, similar to silicon crystals and mechanical strength five times that of engineering plastics. These composites are suitable for a variety of applications, including flexible thin film displays 
(e.g., OLED displays) and windows. Bacterial cellulose pellicles $\sim 10 \mathrm{~mm}$ in thickness were boiled in $3 \% \mathrm{NaOH}$ for several hours to remove the bacterial debris, washed thoroughly and then pressed at $0.3 \mathrm{MPa}$ to remove most of the water prior to drying at $70{ }^{\circ} \mathrm{C}$. Sheets approximately $60 \mu \mathrm{m}$ thick were obtained, with an estimated void content of one third. These voids were vacuum infiltrated with transparent resins including epoxy, acrylic and phenolformaldehyde. Only a 10\% reduction in light transmittance was noted for the bacterial cellulose/epoxy composite in comparison to neat epoxy. Light transmittance was approximately $80 \%$ in the wavelength range $500-800 \mathrm{~nm}$. The tensile strength of the bacterial cellulose/epoxy composites was up to $325 \mathrm{MPa}$ with a Young's modulus of 20-21 GPa, the yield strain of the composites was $2 \%$.

All-cellulose nanocomposites have been processed using surface selective dissolution of cellulose in cellulose solvents, followed by the solvent extraction and cellulose regeneration. This process has been applied to produce all-cellulose composites derived from bacterial cellulose, ${ }^{80}$ microcrystalline cellulose ${ }^{98}$ and aligned ligno-cellulosic fibres ${ }^{99}$ by partial dissolution of cellulose in lithium chloride/ $N, N$-dimethylacetamide, followed by extraction of the solvents and cellulose regeneration in water or methanol. ${ }^{99}$ Surface selective dissolution of bacterial cellulose for periods as short as 10 min resulted in composites with an average tensile strength of $411 \mathrm{MPa}$ and Young's modulus of $18 \mathrm{GPa}$. However, such dissolution invariably disrupts the well-organised cellulose I crystal structure of the cellulose, often the dissolved regions recrystallise and solidify into cellulose II. Toughness has been reported to increase with increasing dissolution time due to this conversion to cellulose II. ${ }^{80,99}$ The technique applied to aligned ramine fibres has resulted in composites with fibre volume fractions as high as $\sim 84 \%$, achieved using dissolution times of just $2 \mathrm{~h} .{ }^{99}$ The authors reported longitudinal tensile strength and Young's modulus of $460 \mathrm{MPa}$ and $28 \mathrm{GPa}$, respectively. ${ }^{99}$ The composites exhibited good interface dominated properties, with transverse tensile strengths reported in the range $22-40 \mathrm{MPa} .{ }^{99}$

\section{TRULY RENEWABLE HIERARCHICAL (NANO)COMPOSITES}

Few of the processing techniques to fabricate renewable nanocomposite discussed thus far have leveraged the properties of the nanofiller in the composite, the blocks to this are principally in achieving good distribution or percolation of the nanofiller throughout the matrix. This section is devoted to work on renewable hierarchical, i.e., fibre reinforced nanocomposites, in which novel attempts are made to (i) structure reinforcements across different length scales, (ii) distribute the nanofiller and (iii) apply conventional processing techniques. Pommet et al..$^{45}$ and Juntaro et al. $^{44,46}$ have conducted extensive work in the direction of producing truly green hierarchical nanocomposites using bacterial cellulose as the reinforcing agent. They cultured bacterial cellulose in the presence of natural fibres, such as sisal and hemp; bacterial cellulose fibrils were grafted in situ onto the surfaces of natural fibres. It was found that strong and highly crystalline bacterial cellulose fibrils preferentially attached, in fact coated the natural fibres thereby creating bacterial cellulose coated natural fibres (see Figs. 6 and 7). These coated fibres helped to enhance the interaction between the fibre and the polymer molecules when processed with CAB and PLA matrices via mechanical interlocking in addition to increasing the surface free energy, leading to composites with improved interfacial adhesion.

The strength of nanocellulose bonding to the natural fibres can be ascribed to extensive hydrogen bonding between the hydroxyl groups present in bacterial cellulose and the cellulose in natural fibres. Simple weight gain measurements before and after the modification of the natural fibres with bacterial cellulose showed that about 5 to $6 \mathrm{wt} \%$ of bacterial cellulose adhered to the fibres as a result of the bacterial modification process. The modification process did not affect the mechanical properties of sisal fibres but it affected those of hemp fibres, as shown in Table II. The exposure of the hemp fibres to the bacterial culture caused a drastic loss of fibre strength as well as Young's modulus, which was due to

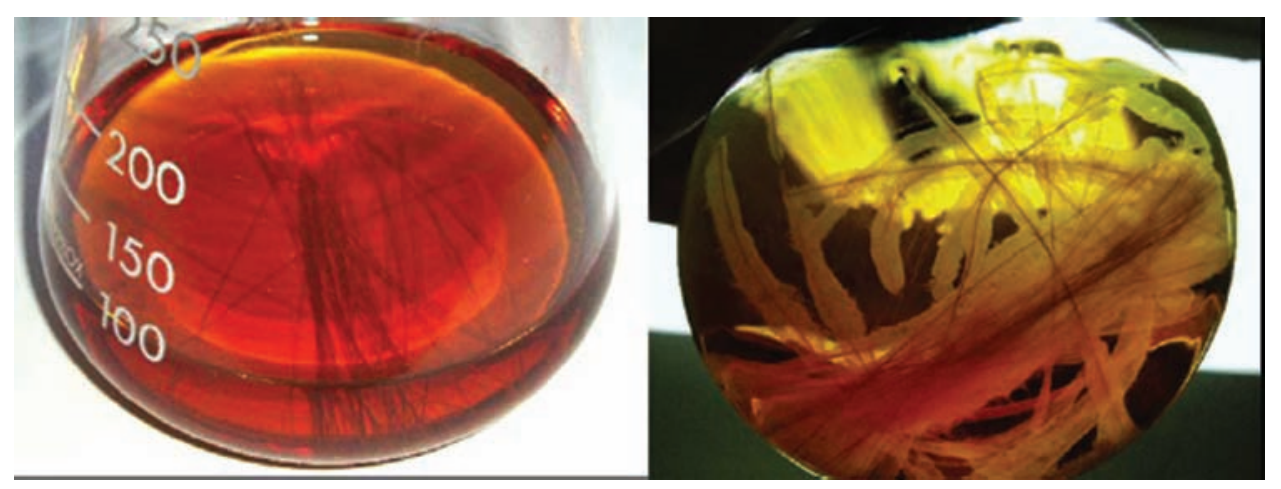

Fig. 6. Sisal fibres in bacterial cellulose culture medium before bacterial cellulose culture (left) and 2 days after bacterial cellulose culture (right). Reprinted with permission from [45], M. Pommet et al., Biomacromolecules 9, 1643 (2008). (C) 2008, ACS publication. 

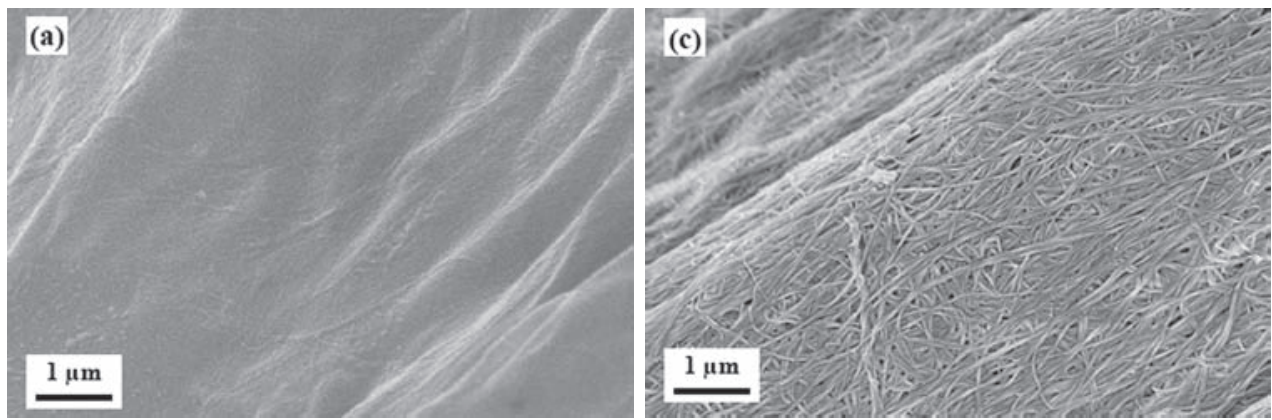

Fig. 7. SEM micrograph of sisal fibre without bacterial cellulose (left) and with bacterial cellulose attached (right). Reprinted with permission from [45], M. Pommet et al., Biomacromolecules 9, 1643 (2008). (C) 2008, ACS publication.

separation (or brooming) of the technical hemp fibres in to smaller individual fibrils as a result of the intrinsically non-cohesive structure of bast fibres.

The deliberate introduction of inherently nano-sized bacterial cellulose onto natural fibre surfaces provides a new means to control the interaction between the modified fibres and a polymer matrix. Coating natural fibres with bacterial cellulose not only facilitates good distribution of the nanocellulose within the matrix (as they are transported by the larger fibres into the matrix) but also resulted in a significantly improved interfacial adhesion of the modified fibres to CAB and PLLA. The apparent interfacial shear strength (IFSS), as a practical measure for the interfacial adhesion, between sisal and CAB and PLLA increased by $46 \%$ and $21 \%$, respectively, while the apparent interfacial shear strength between hemp and $\mathrm{CAB}$ increased as much as $140 \%$. Improved interfacial adhesion enhances the stress transfer efficiency between the fibres and matrix, leading to improvements in the mechanical and thermal performance of composites. The positive effects of the bacterial cellulose coated natural fibres on interfacial shear strength (IFSS) are juxtaposed in comparison to the IFSS determined for the unmodified natural fibres in Table III.

Unidirectional natural fibre reinforced (model) nanocomposites and short fibre nanocomposites were

Table II. Mechanical properties of bacterial cellulose modified natural fibres.

\begin{tabular}{lccc}
\hline Sample & $\begin{array}{c}\text { Young's } \\
\text { modulus } \\
{[\mathrm{GPa}]}\end{array}$ & $\begin{array}{c}\text { Tensile } \\
\text { strength } \\
{[\mathrm{MPa}]}\end{array}$ & $\begin{array}{c}\text { Elongation } \\
\text { at break } \\
{[\%]}\end{array}$ \\
\hline $\begin{array}{l}\text { Pure sisal fibre } \\
\text { Bacterial cellulose } \\
\text { modified sisal fibre }\end{array}$ & $15.0 \pm 1.2$ & $342 \pm 33$ & $2.9 \pm 0.1$ \\
$\begin{array}{l}\text { Bacterial cellulose modified } \\
\text { sisal fibre with purification }\end{array}$ & $12.5 \pm 1.0$ & $324 \pm 33$ & $4.5 \pm 0.4$ \\
$\begin{array}{l}\text { Pure hemp fibre } \\
\text { Bacterial cellulose } \\
\text { modified hemp fibre }\end{array}$ & $21.4 \pm 2.0$ & $286 \pm 31$ & $2.0 \pm 0.2$ \\
$\begin{array}{l}\text { Bacterial cellulose modified } \\
\text { hemp fibre with purification }\end{array}$ & $8.8 \pm 0.7$ & $171 \pm 11$ & $2.9 \pm 0.2$ \\
\hline
\end{tabular}

Source: Reprinted with permission from [45], M. Pommet et al., Biomacromolecules 9, 1643 (2008). () 2008, ACS publication. manufactured by Juntaro et al. ${ }^{44,46,100}$ and Pommet et al. ${ }^{45}$ via compression moulding to investigate the impact of the bacterial cellulose coating process on composite properties. The results are shown in Figure 8. The SEM images showing the interface between the fibres and the matrix are shown in Figure 9. Note that fibres of sisal grafted with bacterial cellulose show improved composite properties in both CAB and PLA matrices over the unmodified sisal fibres; conversely the composites containing bacterial cellulose grafted hemp fibres have the same mechanical properties than those made with unmodified hemp, due to the aforementioned disintegration of the hemp in culture; please note that the hemp fibres only retained $33 \%$ of their virgin fibre mechanical properties. For unidirectional fibre reinforced composites, both the tensile properties parallel and perpendicular to the fibre alignment were found to increase significantly with the bacterial cellulose coatings. In the case of modified sisal reinforced PLLA, the parallel strength and Young's modulus increased by $44 \%$ and $42 \%$, while the off-axis strength and Young's modulus increased by $68 \%$ and $49 \%$, respectively. The method of coating natural fibres with bacterial cellulose also manifested improvements in some short fibre composites. ${ }^{100}$ It was found that the bacterial cellulose modification led to an improvement in the crystallinity of the matrix of PLLA based composites, as well as the improvements in tensile and flexural properties of short sisal fibre-reinforced composites. The presence of the nanocellulose fibrils improved

Table III. Apparent interfacial shear strength of bacterial cellulose grafted natural fibres in CAB and PLLA matrices.

\begin{tabular}{lcc}
\hline Sample & $\begin{array}{c}\text { Interfacial shear } \\
\text { strength to CAB } \\
\text { [MPa] }\end{array}$ & $\begin{array}{c}\text { Interfacial shear } \\
\text { strength to PLLA } \\
\text { [MPa] }\end{array}$ \\
\hline $\begin{array}{l}\text { Pure sisal fibre } \\
\text { Bacterial cellulose }\end{array} \quad 1.02 \pm 0.06$ & $12.1 \pm 0.5$ \\
$\quad$ modified sisal fibre & $1.49 \pm 0.03$ & $14.6 \pm 1.2$ \\
$\begin{array}{l}\text { Pure hemp fibre } \\
\text { Bacterial cellulose } \\
\text { modified hemp fibre }\end{array}$ & $0.76 \pm 0.06$ & N/A \\
\hline
\end{tabular}

Source: Reprinted with permission from [45], M. Pommet et al., Biomacromolecules 9, 1643 (2008). () 2008, ACS publication. 


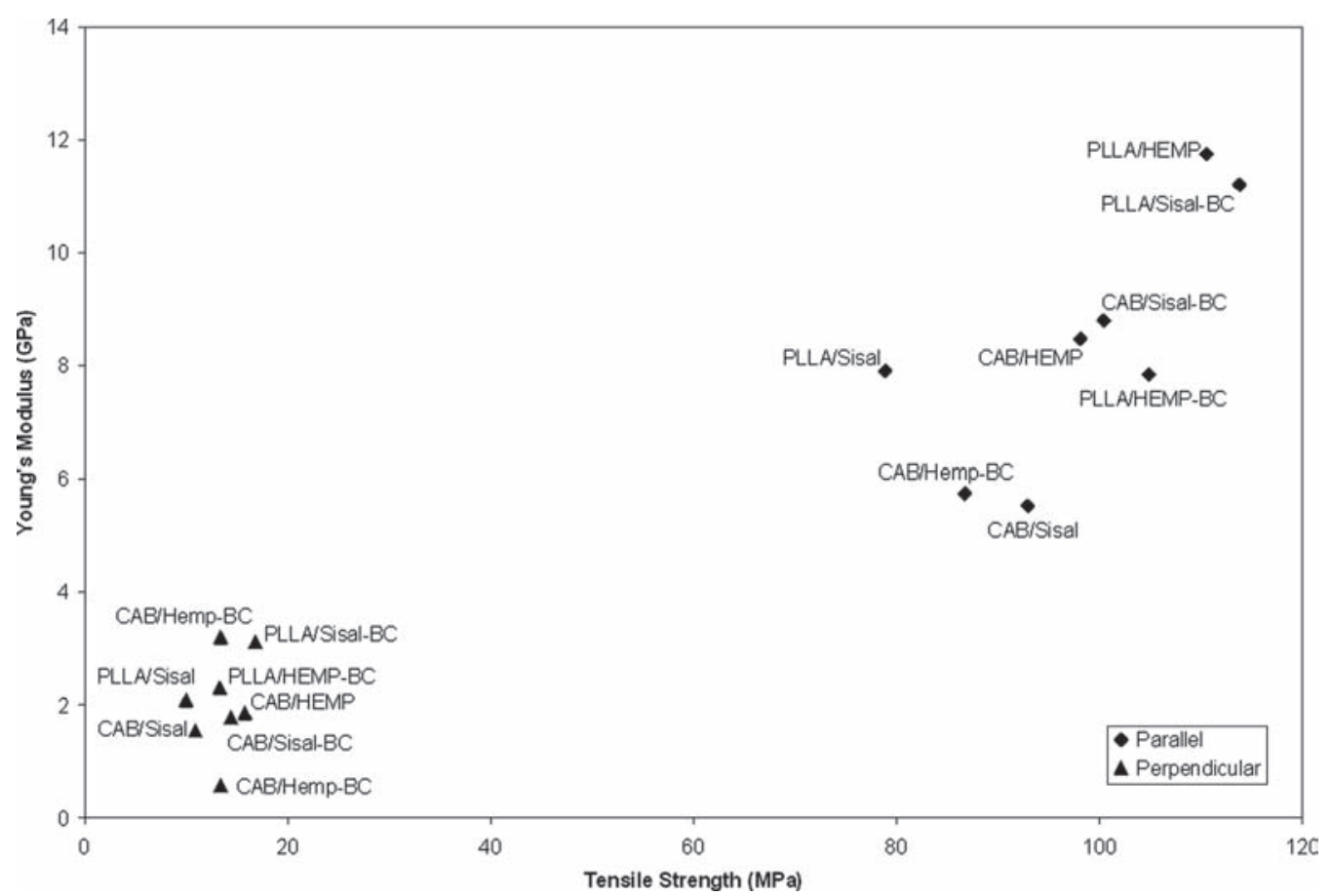

Fig. 8. Mechanical properties of bacterial cellulose modified natural fibre reinforced CAB and PLLA nanocomposites. Reprinted with permission from [44], J. Juntaro et al., Adv. Mater. 20, 3122 (2008). (C) 2008.

the interfacial adhesion between the primary fibres and the polymer as confirmed by microscopy observations of composite fracture surfaces. Nanocellulose materials also contribute a direct reinforcement to the composites. The tensile and flexural properties of the short fibre composites were higher than commercial polypropylene compounds used in interior automotive part applications, indicating its potential in the automotive industry.

Apart from culturing bacteria in the presence of natural fibres to produce hierarchical composites, some

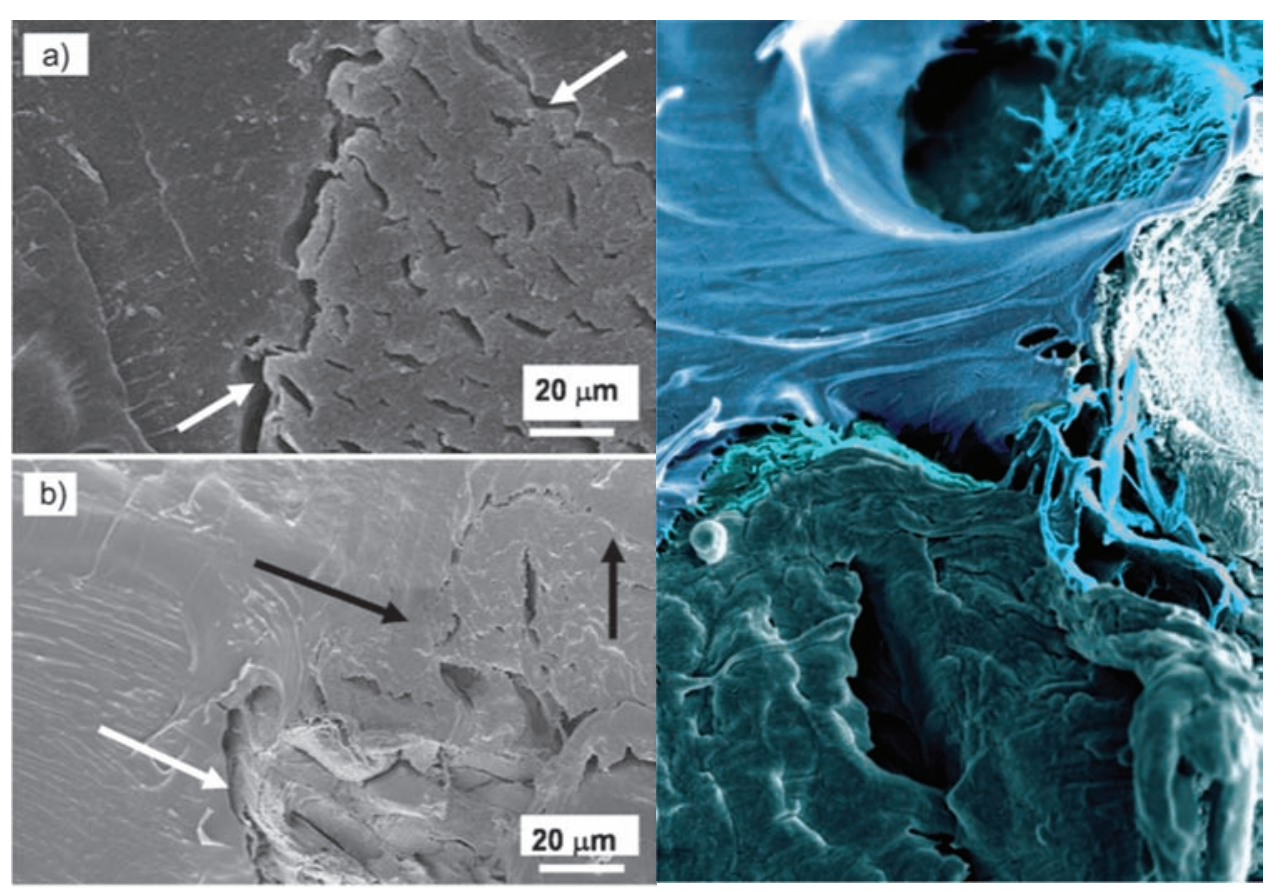

Fig. 9. SEM micrograph of interfacial failure between PLLA and sisal fibre without bacterial cellulose (left) and with bacterial cellulose attached (right). Reprinted with permission from [44], J. Juntaro et al., Adv. Mater. 20, 3122 (2008). (C) 2008, Wiley. 
researchers have added nanocellulose into a matrices reinforced with natural fibres. ${ }^{88,101}$ The authors produced improved PLA/Bamboo fibre/MFC composites, with additions of just 1-2 wt $\%$ of MFC, by increasing the dispersion through processing. Addition of just $1 \mathrm{wt} \% \mathrm{MFC}$ with a high degree of dispersion resulted in an increase in fracture energy of nearly $200 \%$, with a dramatic change in fracture morphology around the bamboo fibre bundles, due to multi-scale effects. These improved properties were achieved through the development of processing techniques to disperse MFC (fibre bundles 2-20 $\mu \mathrm{m}$ in diameter), involving a calenderinging and laboratory-scale three-roll mill. The extracted bamboo fibre bundles were reported to have diameters of $\sim 200 \mu \mathrm{m}$. The shearing induced by the rollers contributed to separate the cellulose fibrils from their swollen, agglomerated state, roller gap settings were decreased progressively from 70 to $5 \mu \mathrm{m}$, with the composite calendered 10 times for each gap setting. Two gap settings (at $35 \mu \mathrm{m}$ and $5 \mu \mathrm{m}$ ) were used to evaluate the effect of dispersion on composite properties and compared to controls composites prepared without calenderinging. After drying, the composites were processed into test specimens via in line twin-screw extrusion and injection moulding, although the temperature used in the extruder was reported low at $140{ }^{\circ} \mathrm{C}$, insinuating that this material was amorphous PLA. The fracture behaviour of these multi-scale composites was investigated by creating single-bundle composites and examining the crack propagation behaviour in pre-notched tensile specimens. Moderate increases in tensile stiffness and strength were recorded for the samples including MFC, yet little variation due to processing technique or reinforcement content were observed. There were however marked differences in the fracture behaviour. Unreinforced PLA and un-milled control composites exhibited brittle fracture with negligible plastic deformation, whereas those calendered composites exhibited significant increase in specimen ductility and strain-to-failure, those produced with the smallest rollergap setting exhibited the most marked differences. The creation of a network of dispersed cellulose resulted in different mechanisms at the micro-scale and inhibited the propagation of cracks. Fracture analysis of the failed samples revealed that the bamboo fibre specimen produced with the un-milled MFC/PLA exhibited a sharp cut to the bamboo fibre on the fracture surface near the crack path, the fracture surface was very smooth, indicating brittle crack propagation. In contrast the specimen calendered at $5 \mu \mathrm{m}$ exhibited a rough fracture surface, suggesting significant plastic deformation. The MFC served to uniformly dissipate strain energy without interfacial failure. Fracture toughness of the hierarchical composites was increased by $90 \%$ from $2 \mathrm{~kJ} \mathrm{~m}^{-2}$ to $3.8 \mathrm{~kJ} \mathrm{~m}^{-2}$ as compared to bamboo fibre reinforced PLA without cellulose dispersed in the matrix. The interfacial shear strength between bamboo fibres and the cellulose-reinforced nanocomposites was found to be $7 \mathrm{MPa}$ compared to $5 \mathrm{MPa}$ (between bamboo fibre and PLA matrix).

Karlsson et al. ${ }^{102}$ demonstrated that the surface fibrillation (via mechanical means) of regenerated cellulose fibres, spun from straw pulp dissolved in $N$-methylmorpholine- $N$-oxide, improved the adhesion between the LDPE matrix and the fibres. Model composites were prepared by embedding untreated and surface-fibrillated single fibres into an LDPE matrix and conducting single fibre fragmentation tests. It was found that the interfacial shear strength increased significantly as a result of surface fibrillation. Some of the micro/nanofibrils on the surface of the fibres appear to be several tens of micrometres in length. The authors hypothesised that the adhesion is due primarily to an interlocking mechanism between the fibrils and the matrix. Although the use of regenerated cellulose and LDPE in this study cannot be regarded as a green composite, the concept used by the authors proved to be useful to create a hierarchical structure within a composite material. This method could be adapted for the use of renewable/natural fibre reinforced bio-based matrix. All these improvements point towards the fact that creating a hierarchical structure within a partially bio-based (nano)composite material is a promising route to create materials with much improved properties.

\section{CONCLUSIONS AND OUTLOOK}

Besides materials synthesis, the theoretical analysis and description of biomimicking composites at multiple scales represents major scientific and engineering challenges and opportunities. The integration of predictive theoretical and numerical studies with experimental methods represents a new frontier in materials research. It is clear that as the volume fractions of the nanofillers in a matrix increase, the matrix crystallisation and interfacial properties will play a more crucial role in the overall mechanical properties of nanocomposites than in their conventional counterparts.

The research reported, so far, demonstrates the potential to improve traditional renewable fibre reinforced composites by dispersing (often modified) cellulose nanofibrils or nanocrystals in the matrix or attaching them onto the primary fibres. However, in order to utilise the advantages of this hierarchical structure, several fundamental and technical issues need to be addressed. The aspect ratio and alignment of the cellulose nanofiller are important factors that determine composite performance and need optimisation, further, novel processing techniques need to be developed to take advantage of the potential that stiff, aligned and staggered high aspect ratio reinforcement fibres have to offer at high loading fractions (>50 vol.\%). Characterisation techniques need to be developed to qualify the orientation and alignment of cellulose in a matrix. The study of hierarchical composites is still in its infancy. The modification of cellulose nanofillers 
should enable a new generation of renewable, multifunctional hierarchical composites materials.

It has been shown that the properties of renewable polymers can be improved by introducing cellulose as reinforcing agent in to polymer matrices. For PLA based cellulose nanocomposites, the tensile strength generally decreases with increasing cellulose content due to agglomeration effects but the Young's modulus increases with increasing cellulose content. The most positive results stem from functionalised $\mathrm{CNFs} / \mathrm{CNCs}$ and novel processing techniques to improve their dispersion, including kneading, rolling and calenderinging and their attachment in culture.

Acknowledgments: The authors would like to thank the UK Engineering and Physical Science Research Council (EPSRC) for funding JJB (Challenging Engineering EP/E007538/1) and KYL (EP/F032005/1).

\section{References}

1. A. K. Mohanty, M. Misra, and G. Hinrichsen, Macromol. Mater. Eng. 276, 1 (2000).

2. I. Siro and D. Plackett, Cellulose 17, 459 (2010).

3. M. H. Gabr, M. A. Elrahman, K. Okubo, and T. Fujii, Composites A 41, 1263 (2010).

4. J. R. Dorgan, B. Braun, J. R. Wegner, and D. M. Knauss, Poly(lactic acids): A brief review, Degradable Polymers and Materials: Principles and Practice, edited by K. Khemani and C. Scholz, ACS (2006).

5. A. Bismarck, S. Mishra, and T. Lampke, Plant fibers as reinforcement for green composites, Natural Fibers, Biopolymers and Biocomposites, edited by A. K. Mohanty, M. Misra, and L. Drzal, CRC Press, Boca Raton (2005).

6. G. Mayer, Science 310, 1144 (2005).

7. P. Fratzl and R. Weinkamer, Prog. Mater. Sci. 52, 1263 (2007).

8. B. H. Ji and H. J. Gao, Ann. Rev. Mater. Res. 40, 77 (2010).

9. G. M. Luz and J. F. Mano, Compos. Sci. Technol. 70, 1777 (2010).

10. H. Lovrette, Rizolli (1985).

11. H. J. Gao, Int. J. Fract. 138, 101 (2006).

12. K. K. Pandey, J. Appl. Polym. Sci. 71, 1969 (1999).

13. P. Fratzl, I. Burgert, and J. Keckes, Z. Metallk. 95, 579 (2004).

14. J. Keckes, I. Burgert, K. Fruhmann, M. Muller, K. Kolln, M. Hamilton, M. Burghammer, S. V. Roth, S. Stanzl-Tschegg, and P. Fratzl, Nat. Mater. 2, 810 (2003).

15. P. Fratzl, I. Burgert, and H. S. Gupta, Phys. Chem. Chem. Phys. 6, 5575 (2004)

16. P. Podsiadlo, S. Paternel, J. M. Rouillard, Z. F. Zhang, J. Lee, J. W. Lee, L. Gulari, and N. A. Kotov, Langmuir 21, 11915 (2005).

17. Z. Y. Tang, N. A. Kotov, S. Magonov, and B. Ozturk, Nat. Mater. 2, 413 (2003).

18. H. Qian, E. S. Greenhalgh, M. S. P. Shaffer, and A. Bismarck, J. Mater. Chem. 20, 4751 (2010).

19. F. H. Gojny, M. H. G. Wichmann, B. Fiedler, W. Bauhofer, and K. Schulte, Composites A 36, 1525 (2005).

20. M. H. G. Wichmann, J. Sumfleth, F. H. Gojny, M. Quaresimin, B. Fiedler, and K. Schulte, Eng. Fract. Mech. 73, 2346 (2006).

21. J. J. Qiu, C. Zhang, B. Wang, and R. Liang, Nanotechnology 18, 275708 (2007).

22. K. J. Green, D. R. Dean, U. K. Vaidya, and E. Nyairo, Composites $A$ 40, 1470 (2009).

23. C. S. Grimmer and C. K. H. Dharan, J. Mater. Sci. 43, 4487 (2008).

24. J. Zhu, A. Imam, R. Crane, K. Lozano, V. N. Khabashesku, and E. V. Barrera, Compos. Sci. Technol. 67, 1509 (2007).
25. K. T. Hsiao, J. Alms, and S. G. Advani, Nanotechnology 14, 791 (2003).

26. M. Arai, Y. Noro, K. I. Sugimoto, and M. Endo, Compos. Sci. Technol. 68, 516 (2008).

27. E. J. Garcia, B. L. Wardle, and A. J. Hart, Composites A 39, 1065 (2008)

28. J. Blanco, E. J. Garcia, R. G. De Villoria, and B. L. Wardle, J. Compos. Mater. 43, 825 (2009).

29. R. B. Mathur, S. Chatterjee, and B. P. Singh, Compos. Sci. Technol. 68, 1608 (2008).

30. K. H. Hung, W. S. Kuo, T. H. Ko, S. S. Tzeng, and C. F. Yan, Composites A 40, 1299 (2009).

31. O. Shafranska, A. Voronov, A. Kohut, X. F. Wu, and I. S. Akhatov, Carbon 47, 3137 (2009).

32. K. L. Kepple, G. P. Sanborn, P. A. Lacasse, K. M. Gruenberg, and W. J. Ready, Carbon 46, 2026 (2008).

33. D. J. Gardner, G. S. Oporto, R. Mills, and M. Samir, J. Adhesion Sci. Technol. 22, 545 (2008).

34. C. Skarr, Wood-Water Relation, Springer Verlag, New York (1988).

35. D. R. Bloch, Polymer Handbook, 4th edn., edited by J. Brandrup, E. H. Immergut, and R. A. Grulke, Wiley Interscience, New York, USA (1999), Vol. 2, pp. VII/497-VII/545.

36. L. Szczesniak, A. Rachocki, and J. Tritt-Goc, Cellulose 15, 445 (2008).

37. M. Iguchi, S. Yamanaka, and A. Budhiono, J. Mater. Sci. 35, 261 (2000).

38. A. N. Nakagaito, S. Iwamoto, and H. Yano, Appl. Phys. A-Mater. Sci. Process. 80, 93 (2005).

39. W. K. Wan, J. L. Hutter, L. Millon, and G. Guhados, Cellulose Nanocomposites: Processing, Characterization, and Properties 938, 221 (2006)

40. S. Yamanaka, K. Watanabe, N. Kitamura, M. Iguchi, S. Mitsuhashi, Y. Nishi, and M. Uryu, J. Mater. Sci. 24, 3141 (1989).

41. P. Ross, R. Mayer, and M. Benziman, Microbiol. Rev. 55, 35 (1991).

42. A. J. Brown, J. Chem. Soc. Trans. 49, 172 (1886).

43. H. Mark and G. Susich, Z. Physik Chem. 4, 431 (1929).

44. J. Juntaro, M. Pommet, G. Kalinka, A. Mantalaris, M. S. P. Shaffer, and A. Bismarck, Adv. Mater. 20, 3122 (2008).

45. M. Pommet, J. Juntaro, J. Y. Y. Heng, A. Mantalaris, A. F. Lee, K. Wilson, G. Kalinka, M. S. P. Shaffer, and A. Bismarck, Biomacromolecules 9, 1643 (2008).

46. J. Juntaro, M. Pommet, A. Mantalaris, M. Shaffer, and A. Bismarck, Compos. Interfaces 14, 753 (2007).

47. T. Nishino, I. Matsuda, and K. Hirao, Macromolecules 37, 7683 (2004)

48. Y. Nishi, M. Uryu, S. Yamanaka, K. Watanabe, N. Kitamura, M. Iguchi, and S. Mitsuhashi, J. Mater. Sci. 25, 2997 (1990).

49. M. Nogi, S. Ifuku, K. Abe, K. Handa, A. N. Nakagaito, and H. Yano, Appl. Phys. Lett. 88, 133124 (2006).

50. V. Favier, H. Chanzy, and J. Y. Cavaille, Macromolecules 28,6365 (1995).

51. W. Gindl and J. Keckes, Compos. Sci. Technol. 64, 2407 (2004).

52. L. Petersson and K. Oksman, Compos. Sci. Technol. 66, 2187 (2006).

53. L. Heux, G. Chauve, and C. Bonini, Langmuir 16, 8210 (2000)

54. Y. Okahisa, A. Yoshida, S. Miyaguchi, and H. Yano, Compos. Sci. Technol. 69, 1958 (2009).

55. M. N. Angles and A. Dufresne, Macromolecules 34, 2921 (2001).

56. M. Grunert and W. T. Winter, J. Polym. Environ. 10, 27 (2002).

57. D. Bondeson and K. Oksman, Composites A 38, 2486 (2007).

58. N. Ljungberg, J. Y. Cavaille, and L. Heux, Polymer 47, 6285 (2006)

59. L. Chazeau, J. Y. Cavaille, G. Canova, R. Dendievel, and B. Boutherin, J. Appl. Polym. Sci. 71, 1797 (1999). 
60. M. Samir, F. Alloin, J. Y. Sanchez, and A. Dufresne, Polymer 45, 4149 (2004).

61. L. Heux, E. Dinand, and M. R. Vignon, Carbohydr. Polym. 40, 115 (1999).

62. J. F. Revol, H. Bradford, J. Giasson, R. H. Marchessault, and D. G. Gray, Int. J. Biol. Macromol. 14, 170 (1992)

63. J. F. Revol, L. Godbout, X. M. Dong, D. G. Gray, H. Chanzy, and G. Maret, Liq. Cryst. 16, 127 (1994).

64. M. Samir, F. Alloin, and A. Dufresne, Biomacromolecules 6, 612 (2005).

65. P. Terech, L. Chazeau, and J. Y. Cavaille, Macromolecules 32, 1872 (1999).

66. J. Araki, M. Wada, S. Kuga, and T. Okano, Colloids Surf. A 142, 75 (1998).

67. M. M. D. Lima and R. Borsali, Macromol. Rapid Comm. 25, 771 (2004).

68. D. Bondeson, A. Mathew, and K. Oksman, Cellulose 13, 171 (2006).

69. J. R. Capadona, K. Shanmuganathan, D. J. Tyler, S. J. Rowan, and C. Weder, Science 319, 1370 (2008).

70. Y. Habibi, L. A. Lucia, and O. J. Rojas, Chem. Rev. 110, 3479 (2010).

71. L. H. C. Mattoso, E. S. Medeiros, D. A. Baker, J. Avloni, D. F. Wood, and W. J. Orts, J. Nanosci. Nanotechnol. 9, 2917 (2009).

72. K. Y. Lee, J. J. Blaker, and A. Bismarck, Compos. Sci. Technol. 69, 2724 (2009).

73. B. Braun and J. R. Dorgan, Biomacromolecules 10, 334 (2009).

74. J. J. Blaker, K. Y. Lee, X. X. Li, A. Menner, and A. Bismarck, Green Chemistry 11, 1321 (2009).

75. Y. Okita, T. Saito, and A. Isogai, Biomacromolecules 11, 1696 (2010).

76. M. Hirota, K. Furihata, T. Saito, T. Kawada, and A. Isogai, Angew. Chem.-Intern. Ed. 49, 7670 (2010).

77. H. Fukuzumi, T. Saito, Y. Okita, and A. Isogai, Polymer Degrad. and Stability 95, 1502 (2010).

78. Y. Habibi and A. Dufresne, Biomacromolecules 9, 1974 (2008).

79. C. Bonini, L. Heux, J. Y. Cavaille, P. Lindner, C. Dewhurst, and P. Terech, Langmuir 18, 3311 (2002).

80. N. Soykeabkaew, C. Sian, S. Gea, T. Nishino, and T. Peijs, Cellulose 16, 435 (2009).

81. S. Berlioz, S. Molina-Boisseau, Y. Nishiyama, and L. Heux, Biomacromolecules 10, 2144 (2009).

82. A. Dufresne, Molecules 15, 4111 (2010).
83. D. G. Liu, T. H. Zhong, P. R. Chang, K. F. Li, and Q. L. Wu, Bioresour. Technol. 101, 2529 (2010).

84. A. H. Pei, Q. Zhou, and L. A. Berglund, Compos. Sci. Technol. 70,815 (2010).

85. D. G. Gray, Cellulose 15, 297 (2008).

86. E. Ten, J. Turtle, D. Bahr, L. Jiang, and M. Wolcott, Polymer 51, 2652 (2010).

87. L. Suryanegara, A. N. Nakagaito, and H. Yano, Cellulose 17, 771 (2010).

88. K. Okubo, T. Fujii, and E. T. Thostenson, Composites A 40, 469 (2009).

89. M. Jonoobi, J. Harun, A. P. Mathew, and K. Oksman, Comp. Sci. Techn. 70, 1742 (2010).

90. A. P. Mathew, K. Oksman, and M. Sain, J. Appl. Polym. Sci. 97, 2014 (2005).

91. M. S. Huda, A. K. Mohanty, L. T. Drzal, E. Schut, and M. Misra, J. Mater. Sci. 40, 4221 (2005).

92. A. J. de Menezes, G. Siqueira, A. A. S. Curvelo, and A. Dufresne, Polymer 50, 4552 (2009).

93. K. Oksman, A. P. Mathew, D. Bondeson, and I. Kvien, Compos. Sci. Technol. 66, 2776 (2006).

94. P. Tingaut, T. Zimmermann, and F. Lopez-Suevos, Biomacromolecules 11, 454 (2010).

95. Q. Zhou, E. Malm, H. Nilsson, P. T. Larsson, T. Iversen, L. A. Berglund, and V. Bulone, Soft Matter 5, 4124 (2009).

96. K. Abe, F. Nakatsubo, and H. Yano, Compos. Sci. Technol. 69, 2434 (2009).

97. H. Yano, J. Sugiyama, A. N. Nakagaito, M. Nogi, T. Matsuura, M. Hikita, and K. Handa, Adv. Mater. 17, 153 (2005).

98. A. Abbott and A. Bismarck, Cellulose 17, 779 (2010).

99. N. Soykeabkaew, N. Arimoto, T. Nishino, and T. Peijs, Compos. Sci. Technol. 68, 2201 (2008).

100. J. Juntaro, Environmentally friendly hierarchical composites, $\mathrm{Ph} . \mathrm{D}$. Thesis, Imperial College London, London (2009).

101. K. Okubo, T. Fujii, and N. Yamashita, JSME Intern. J. 48, 199 (2005).

102. J. O. Karlsson, J. F. Blachot, A. Peguy, and P. Gatenholm, Polymer Composites 17, 300 (1996).

103. R. Rusli and S. J. Eichhorn, Appl. Phys. Lett. 93 (2008).

104. A. Sturcova, G. R. Davies, and S. J. Eichhorn, Biomacromolecules 6, 1055 (2005).

105. Y. C. Hsieh, H. Yano, M. Nogi, and S. J. Eichhorn, Cellulose 15, 507 (2008).

106. S. J. Eichhorn and R. J. Young, Cellulose 8, 197 (2001).

Received: 7 January 2011. Revised/Accepted: 6 February 2011. 